\title{
Notes on the vocalizations of Hellmayr's Pipit (Anthus hellmayri)
}

Peter Boesman

In the following we briefly analyze and compare voice of the different races of Hellmayr's Pipit (Anthus hellmayri). We also try to quantify the extent of any vocal differences using the criteria proposed by Tobias et al. (2010), as a support for taxonomic review.

We have made use of sound recordings available on-line from Xeno Canto (XC).

Some examples of song illustrated with sonograms:

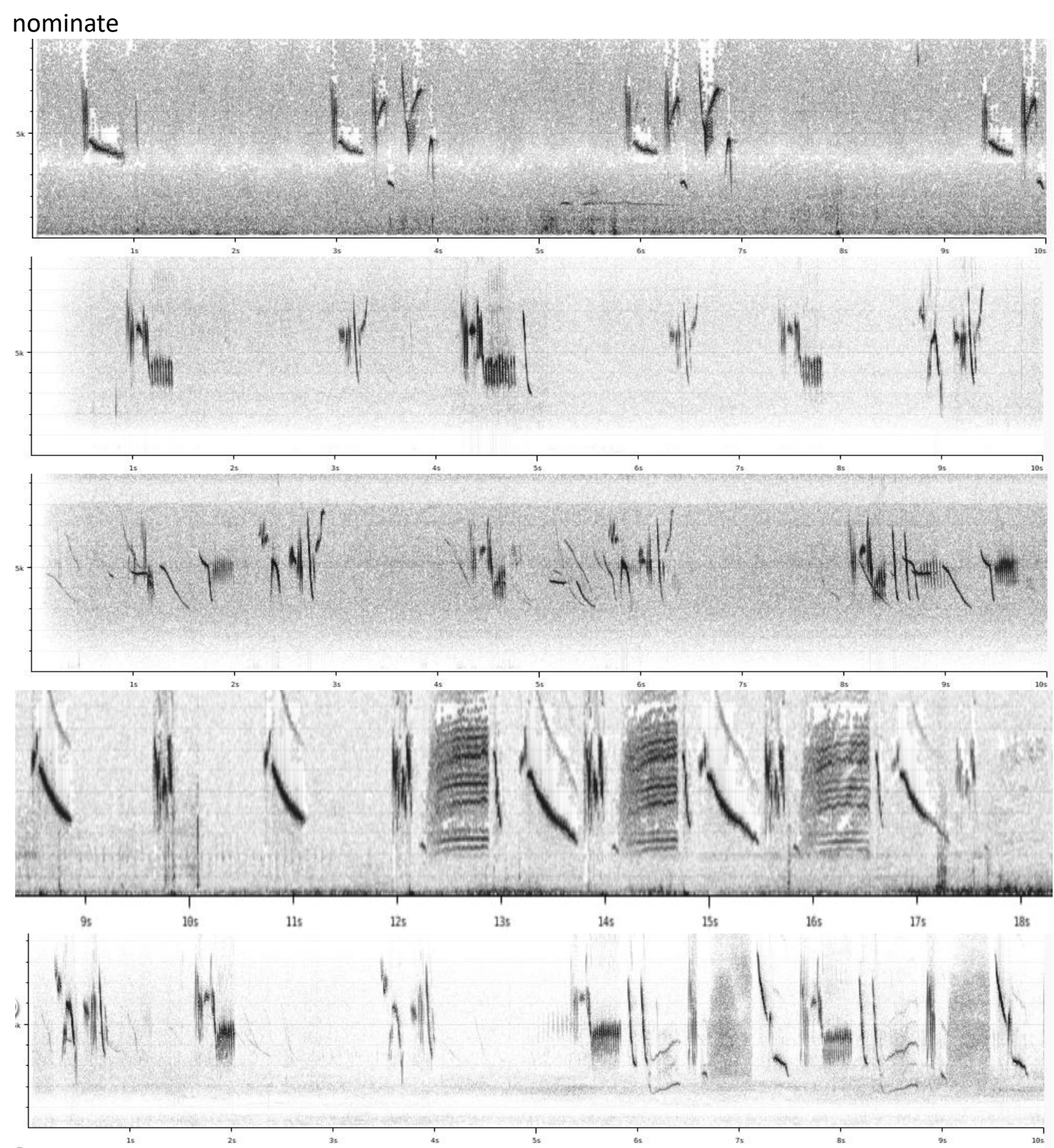


HANDBOOK OF THE

BIRDPFIYUE WORLD ORNITHOLOGICAL NOTES

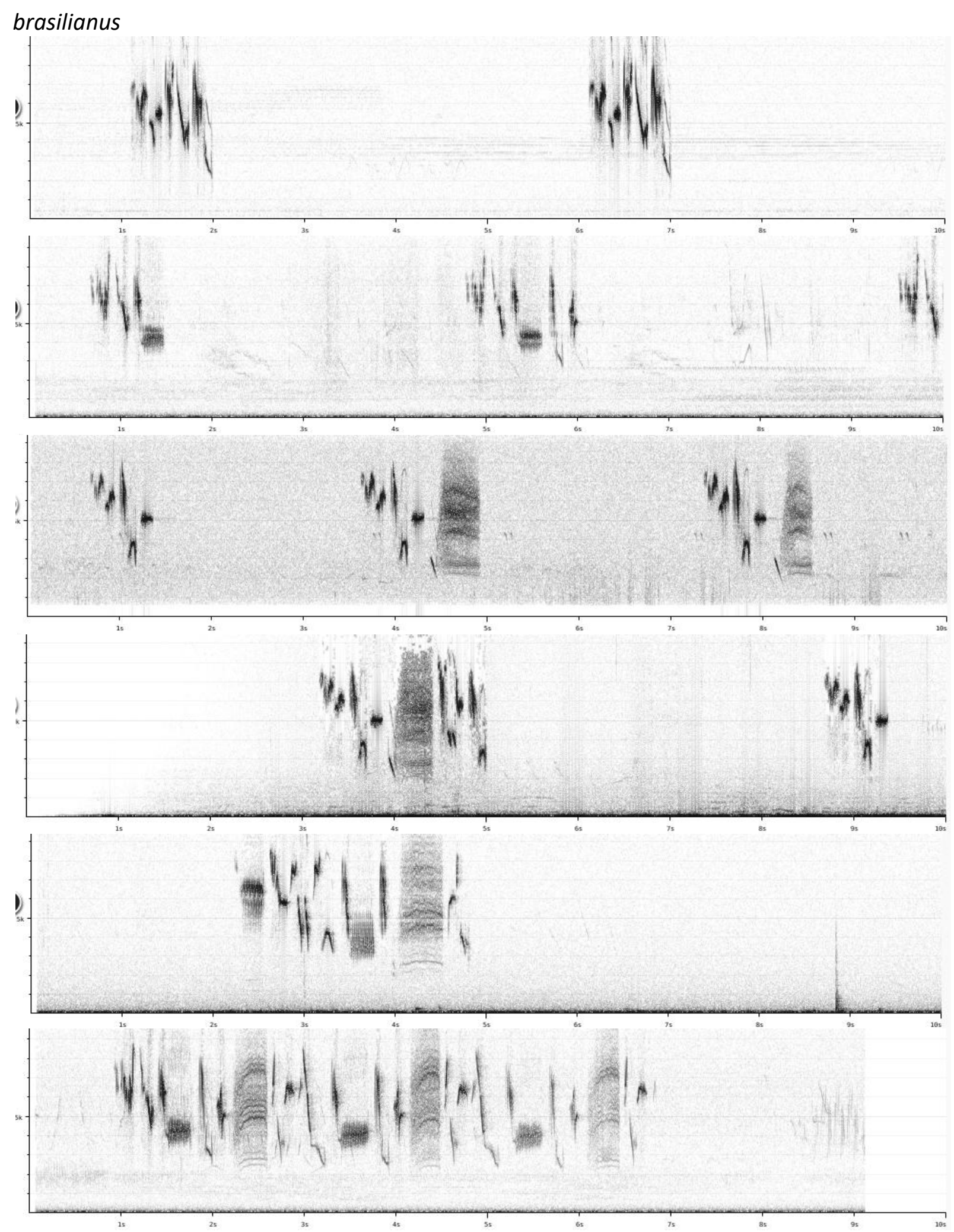



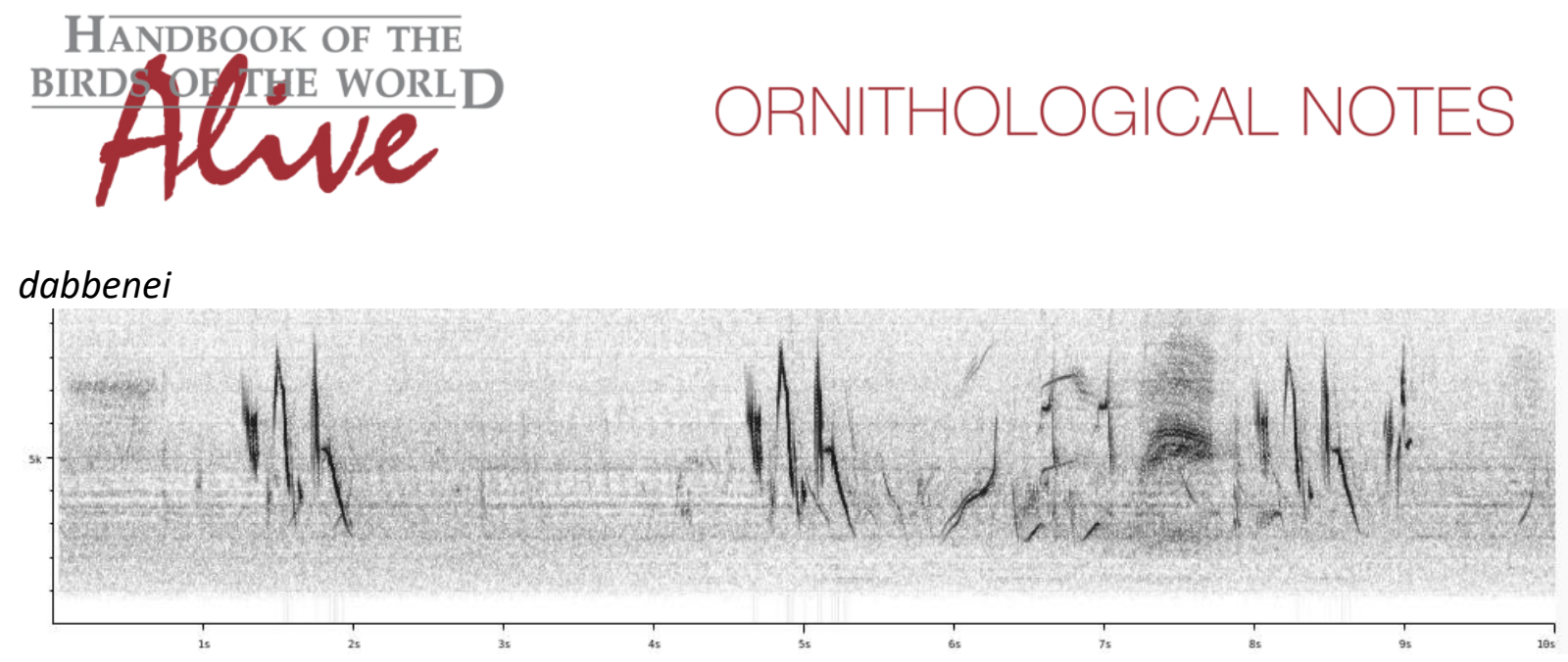

Song in general is quite variable, often just a short sweet phrase of some 3-6 notes (duration c 1s), but may be much more elaborated. In most songs a burry or buzzy note is present. Nominate and brasilianus don't seem to have significant differences in song: both races have short burry notes in the range $3-5 \mathrm{kHz}$, longer buzzy notes with similar frequency properties and note shapes in both cases fairly similar. Basic sound parameters of other notes similar, a larger set of recordings would be needed to determine whether some notes are truly unique to a race, but in any case this will not lead to a high vocal score.

All in all, song difference is not at all obvious, which seems to contradict earlier statements in HBW (HBW Alive: Tyler et al. 2016). All other Anthus pipits of the region (Correndera $A$. correndera, Ochre-breasted A. nattereri, Short-billed A. furcatus, Paramo A. bogotensis and Yellowish Pipit $A$. lutescens) have a distinctive song, far more obvious than the possible differences between these two races.

It would this seem that there are no clear significant vocal differences between the races of Hellmayr's Pipit.

This note was finalized on 3rd May 2016, using sound recordings available on-line at that moment. We would like to thank in particular the many sound recordists who placed their recordings for this species on XC.

\section{References}

Tobias, J.A., Seddon, N., Spottiswoode, C.N., Pilgrim, J.D., Fishpool, L.D.C. \& Collar, N.J. (2010). Quantitative criteria for species delimitation. Ibis 152(4): 724-746.

Tyler, S. \& de Juana, E. (2016). Hellmayr's Pipit (Anthus hellmayri). In: del Hoyo, J., Elliott, A., Sargatal, J., Christie, D.A. \& de Juana, E. (eds.). Handbook of the Birds of the World Alive. Lynx Edicions, Barcelona. (retrieved from http://www.hbw.com/node/57796 on 3 May 2016).

\section{Recommended citation}

Boesman, P. (2016). Notes on the vocalizations of Hellmayr's Pipit (Anthus hellmayri). HBW Alive Ornithological Note 350. In: Handbook of the Birds of the World Alive. Lynx Edicions, Barcelona. (retrieved from http://www.hbw.com/node/1252881 on 27 October 2016). 